\title{
PENYEBAB CHANGE ORDER PADA PROYEK KONSTRUKSI GEDUNG BERTINGKAT
}

\author{
Adi Ananias Ardine ${ }^{1}$ dan Hendrik Sulistio² \\ ${ }^{1}$ Program Studi Sarjana Teknik Sipil, Universitas Tarumanagara, Jl. Letjen S. Parman No.1 Jakarta \\ adi.325150121@stu.untar.ac.id \\ ${ }^{2}$ Program Studi Sarjana Teknik Sipil, Universitas Tarumanagara, J1. Letjen S. Parman No.1 Jakarta \\ hendriks@ft.untar.ac.id
}

Masuk: 19-06-2020, revisi: 30-07-2020, diterima untuk diterbitkan: 30-07-2020

\begin{abstract}
The number of high rise building construction projects in Jabodetabek area continues to grow. The main reason is increasing population of the region, so that development in the vertical direction becomes a solution. There are three important criteria in every construction project, namely cost, quality, and time. These criteria must be agreed upon and regulated in the form of a contract. Based on prior research, change orders cannot be avoided in every construction project. Change order can give complex impact and able to harm related parties. To minimize and anticipate the occurrence of change orders, it is necessary to know the factors that can cause changes in a contract. The factors that have been determined from the results of the literature study are compiled into a questionnaire to find out the main causes of change orders. The questionnaire was distributed to owners, contractors and consultants in high rise building projects in Jabodetabek area. PLS-SEM is used as a method for analyzing data in this study with the help of the smartPLS 3.0 program. From the results of the analysis carried out, obtained two factors that have a significant influence on the change order, namely construction factors and administrative factors.
\end{abstract}

Keywords: Causes of Change Order; Change Order; PLS-SEM; Jabodetabek; High-Level Building

\begin{abstract}
ABSTRAK
Jumlah proyek konstruksi gedung bertingkat di wilayah Jabodetabek terus bertumbuh. Alasan utama karena kondisi wilayah yang semakin padat, sehingga pengembangan pembangunan ke arah vertikal menjadi solusi. Terdapat tiga kriteria penting yang menjadi fokus dalam setiap proyek konstruksi, yaitu biaya, mutu, dan waktu. Kriteria-kriteria tersebut harus disepakati dan diatur oleh pihak-pihak yang terlibat sesuai dengan ketentuan peraturan yang berlaku dalam bentuk kontrak. Berdasarkan penelitian terdahulu, perubahan atau change order merupakan hal yang umum dan tidak dapat dihindari dalam setiap proyek konstruksi. Change order memberikan dampak yang kompleks, sehingga sangat berpengaruh terhadap kinerja suatu proyek konstruksi dan dapat merugikan pihak-pihak yang terlibat di dalamnya. Untuk meminimalisir serta mengantisipasi terjadinya change order, maka perlu untuk mengetahui faktor-faktor yang dapat menyebabkan perubahan dalam suatu kontrak pada proyek konstruksi gedung bertingkat. Faktor-faktor yang sudah ditentukan dari hasil studi literatur disusun menjadi sebuah kuesioner untuk mengetahui penyebab utama dari change order. Penyebaran kuesioner tersebut dilakukan terhadap owner, kontraktor, dan konsultan pada proyek gedung bertingkat di wilayah Jabodetabek. PLS-SEM digunakan sebagai metode untuk menganalisis data pada penelitian ini dengan bantuan program smartPLS 3.0. Dari hasil analisis yang dilakukan, didapat dua faktor yang memiliki nilai pengaruh signifikan terhadap change order, yaitu faktor konstruksi dan faktor administrasi.
\end{abstract}

Kata kunci: Penyebab Change Order; Change Order; PLS-SEM; Jabodetabek; Gedung Bertingkat

\section{PENDAHULUAN}

Secara umum, proyek konstruksi dapat didefinisikan sebagai suatu rangkaian kegiatan yang saling berkaitan satu dengan yang lain guna mencapai suatu sasaran tertentu (bangunan/konstruksi) dalam batasan waktu, biaya dan mutu tertentu. Sebelum suatu proyek konstruksi dapat terlaksana, terdapat serangkaian kegiatan yang cukup panjang hingga kontrak dapat tercipta dan suatu proyek dapat direalisasikan. Fungsi kontrak ini adalah untuk mengatur dan membatasi semua hak dan kewajiban segala pihak yang terlibat sehingga tujuan proyek dapat tercapai. Namun hampir seluruh proyek konstruksi di Indonesia mengalami terjadinya perubahan kontrak, baik diselenggarakan oleh pemerintah maupun swasta (Sulistio \& Waty,2008). Perubahan ini lebih dikenal sebagai change order. 
Change order dapat memberikan dampak negatif secara langsung seperti peningkatan pada frekuensi perencanaan, peningkatan manajemen proyek dan kebutuhan pengawasan, penggunaan tenaga kerja yang berlebihan (overmanning), kompresi/penekanan jadwal, pekerjaan tidak sesuai dengan urutan, dan kurangnya ketersediaan sumber daya dalam memenuhi persyaratan perubahan (Hanna et al., 1992), yang dapat menyebabkan penurunan produktivitas, pembengkakan biaya, dan penundaan proyek. Selain itu change order juga dapat memberikan dampak negatif secara secara tidak langsung yaitu terjadinya perselisihan antara pemilik dan kontraktor. Dalam beberapa kasus, change order dapat menyebabkan kebingungan dan efek yang merusak lingkungan (Alnuaimi et al., 2010). Sebuah studi kasus berdasarkan laporan kantor audit nasional Taiwan 1998 kecacatan utama pada proyek pemerintah adalah begitu banyaknya change order, yang dapat menyebabkan proyek terlambat dan biaya membengkak (Hsieh et al., 2004). Begitu kompleksnya dampak dari change order, sehingga sangat berpengaruh pada kinerja suatu proyek konstruksi.

Faktor penyebab change order sangat beragam dan unik, setiap proyek memiliki penyebab yang berbeda antara satu proyek dengan yang lainnya. Faktor penyebab change order dapat disebabkan oleh pengguna jasa maupun penyedia jasa. Faktor penyebab yang berasal dari pengguna jasa diantaranya keinginan pengguna jasa untuk merubah spesifikasi konstruksi, keinginan mempercepat pekerjaan karena kebutuhan pasar, dan pertimbangan politik. Sedangkan faktor penyebab yang berasal dari penyedia jasa antara lain sumber daya kontraktor tidak sesuai dengan lingkup pekerjaan di mana tenaga ahli dan peralatan penunjang tidak memadai dalam penyelesaian pekerjaan, akibatnya jadwal yang ditetapkan selalu berubah (Sapulette, 2009).

Tujuan dari penelitian ini adalah mengetahui faktor yang mempengaruhi terjadinya change order pada proyek konstruksi gedung bertingkat di wilayah Jabodetabek. Diharapkan, dengan mengetahui faktor-faktor yang dapat menyebabkan perubahan dalam suatu kontrak pada proyek konstruksi gedung bertingkat di wilayah Jabodetabek, dapat menjadi masukan bagi para pihak yang akan terlibat dalam proyek konstruksi gedung bertingkat kedepannya, terutama pihak owner dan kontraktor agar dapat meminimalisasi dan mengantisipasi change order pada masa yang akan datang.

\section{Change order}

Change order atau contract change order merupakan perubahan dalam lingkup kontrak, persetujuan terhadap revisi penjadwalan, kumpulan dari modifikasi-modifikasi lainnya dan berbentuk formulir standar yang terdiri atas ringkasan dari deskripsi perubahan dan dampak dari perubahan tersebut terhadap kontrak, baik biaya maupun waktu proyek (Barrie \& Paulson, 1992). Change order merupakan hal umum dan sering terjadi dalam proyek konstruksi, baik pada proyek pemerintah maupun proyek swasta (Sulistio \& Waty, 2012). Change order pada proyek konstruksi dapat terjadi pada masa awal, pertengahan, dan akhir pelaksanaan proyek dan melibatkan pihak-pihak yang terlibat seperti pemilik dan kontraktor (Sapulette, 2009). Perubahan-perubahan pada design awal tersebut dapat terjadi akibat alasan teknis, estetika, kepraktisan, finansial, atau perubahan atas kehendak pemilik proyek sendiri (Hansen, 2017) dan kebutuhan lapangan guna menyempurnakan pekerjaan fisik agar sesuai dengan tujuan semula proyek (Sulistio \& Wibowo, 2009).

\section{Indikasi change order}

Change order selalu dihubungkan dengan hilangnya produktivitas, tetapi (Hsieh et al., 2004) menyatakan dalam dampak yang berbeda. Dampak change order yang berbeda ini dinyatakan dalam dua aspek yakni varian biaya dan varian margin. Varian biaya adalah harga kontrak awal sebelum ada perubahan. Varian margin adalah varian yang berhubungan dengan pengurangan atau penambahan biaya dari adanya aktivitas baru/ aktivitas yang berubah. Dampak jadwal juga mudah diketahui, karena hanya berupa perpanjangan/ penambahan waktu pada jalur kritis yang menyebabkan pengunduran waktu penyelesaian proyek.

\section{Pengelompokan penyebab change order}

Dari beberapa penelitian mengenai penyebab change order, dirangkum menjadi 37 penyebab, yang kemudian di golongkan kedalam 4 kelompok utama, yaitu:

- Faktor konstruksi

- Ketidaksesuaian antara gambar design dengan kondisi lapangan

- Pekerjaan tambahan untuk pekerjaan dibawah tanah

- Perubahan design

- Perubahan ruang lingkup pekerjaan pada tahap pelaksanaan konstruksi

- Perubahan spesifikasi

- Kesalahan dalam perencanaan konstruksi

- Penghentian pekerjaan sementara

○ Jadwal yang terlalu padat 
- Kondisi bawah tanah yang berbeda terhadap hasil penyelidikan

- Spesifikasi atau kriteria design engineering yang kurang lengkap

- Perubahan pekerjaan yang telah selesai

- Rembesan air tanah saat proses penggalian

- Perubahan kondisi lapangan proyek

- Percepatan jadwal

- Peningkatan penyelidikan kondisi tanah

- Perubahan metode kerja

- Pertimbangan keselamatan kerja

- Faktor administrasi

- Koordinasi yang terlambat disampaikan

- Perubahan berdasarkan perlindungan lingkungan

- Konflik kontrak dan perselisihan

- Perubahan kebijakan politik/ekonomi pemerintah

- Kontrak yang tidak lengkap

- Pasal-pasal kontrak yang kurang jelas

- Pengiriman material yang tidak sesuai spesifikasi

- Faktor pihak yang terlibat

- Percepatan pekerjaan atas perintah owner

- Kebijakan peraturan dari pihak owner

- Jadwal owner terlambat

- Penundaan pekerjaan karena permintaan owner

- Kegagalan owner menyediakan sites, alat atau material

- Jadwal kontraktor terlambat

- Intervensi pihak ketiga

○ Kinerja pihak ketiga yang kurang baik

- Faktor lain-lain

- Kejadian tak terduga seperti kebakaran atau kerusakan pada alat berat

- Cuaca buruk

- Penurunan tanah

- Bencana alam

○ Konflik antar buruh

\section{METODE PENELITIAN}

\section{Studi literatur}

Pada tahapan studi literatur, penulis melakukan tahap studi literatur melalui undang-undang, peraturan presiden, jurnal-jurnal, dan buku-buku untuk mengerti lingkup penelitian yang dimaksud serta memahami lebih dalam terhadap objek yang akan diteliti. Hasil dari studi literatur digunakan sebagai landasan teori dan pedoman dalam penelitian ini.

\section{Pengumpulan data}

Proses pengumpulan data dilakukan melalui penyebaran kuesioner dengan target responden adalah kontraktor, konsultan, dan owner dari proyek yang bersangkutan, serta melakukan wawancara terhadap pihak-pihak terkait pada beberapa proyek data yang dijadikan sampel. Kuesioner dibuat dengan metode modifikasi berdasarkan kuesioner yang diambil dari penelitian Sapulette (2009). Untuk alur penelitian dapat dilihat pada gambar 1. 


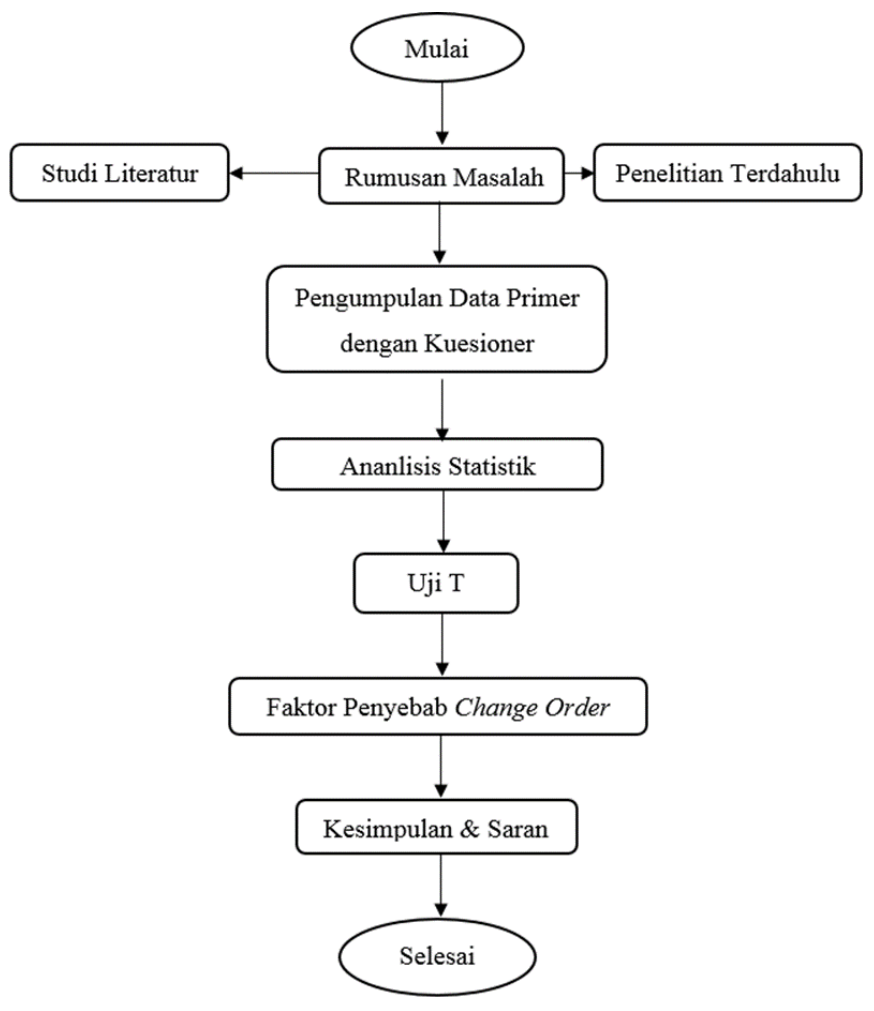

Gambar 1. Diagram alir

\section{Metode analisis data}

Analisis data menggunakan SmartPLS 3.0. Alasan penggunaan PLS selain digunakan untuk menkonfirmasi teori, PLS juga dapat digunakan untuk menjelaskan ada atau tidaknya hubungan antara variabel laten.

Dalam analisis dengan menggunakan PLS ada 2 hal yang dilakukan yaitu:

- Menilai outer model atau measurement model

Ada tiga kriteria untuk menilai outer model yaitu convergent validity, discriminant validity dan composite reliability. convergent validity dari model pengukuran dengan refleksif indikator dinilai berdasarkan korelasi antara item score/ component score yang dihitung dengan PLS. Ukuran refleksif individual dikatakan tinggi jika berkorelasi lebih dari 0,70 dengan konstruk yang diukur. Namun (Chin, 1998 dalam Ghozali, 2014) untuk penelitian tahap awal dari pengembangan skala pengukuran nilai loading 0,5 sampai 0,6 dianggap cukup memadai.

Discriminant validity dari model pengukuran dengan refleksif indikator dinilai berdasarkan cross loading pengukuran dengan konstruk. Jika korelasi konstruk dengan item pengukuran lebih besar daripada ukuran konstruk lainnya, maka hal tersebut menunjukkan konstruk laten memprediksi ukuran pada blok mereka lebih baik daripada ukuran pada blok lainnya.

Metode lain untuk menilai discriminant validity adalah membandingkan nilai square root of average variance extracted (AVE) setiap konstruk dengan korelasi antara konstruk dengan konstruk lainnya dalam model (Ghozali, 2014). Jika nilai akar kuadrat AVE setiap konstruk lebih besar daripada nilai korelasi antar konstruk dengan konstruk lainnya dalam model, maka dikatakan memiliki nilai discriminant validity yang baik.

Pengukuran ini dapat digunakan untuk mengukur reliabilitas component score variabel laten dan hasilnya lebih konservatif dibandingkan dengan composite reliability. Direkomendasikan nilai AVE harus lebih besar 0,50 (Fornell dan Larcker, 1981 dalam Ghozali, 2014). Composite reability yang mengukur suatu konstruk dapat dievaluasi dengan dua macam ukuran yaitu internal consistency dan cronbach's alpha (Ghozali, 2014).

- Menilai inner model atau structural model

Pengujian inner model atau model struktural dilakukan untuk melihat hubungan antara konstruk, nilai signifikansi dan R-square dari model penelitian. Model struktural dievaluasi dengan menggunakan R-square untuk konstruk dependen, Q-square test untuk predictive relevance dan uji t serta signifikansi dari koefisien parameter jalur struktural. 


\section{HASIL DAN PEMBAHASAN}

\section{Variabel penelitian}

Varibel penelitian yang digunakan terdiri dari 4 variabel eksogen yaitu faktor konstruksi (X1), faktor administrasi (X2), faktor pihak terkait (X3), dan faktor lain-lain (X4) dan satu variabel endogen yaitu change order (Y1). Variabel X1 memiliki 17 indikator, variabel X2 memiliki 7 indikator, variabel X3 memiliki 8 indikator, variabel X4 memiliki 5 indikator dan variable Y1 memiliki 5 indikator. Variabel-variabel tersebut dapat dilihat pada Tabel 1 berikut.

Tabel 1. Variabel penelitian

\begin{tabular}{|c|c|}
\hline Var. & Faktor penyebab change order \\
\hline $\mathrm{X} 1$ & Faktor konstruksi \\
\hline $\mathrm{X} 1.1$ & Ketidaksesuaian antara gambar design dengan kondisi lapangan \\
\hline $\mathrm{X} 1.2$ & Pekerjaan tambahan untuk pekerjaan dibawah tanah \\
\hline $\mathrm{X} 1.3$ & Perubahan design \\
\hline $\mathrm{X} 1.4$ & Perubahan ruang lingkup pekerjaan pada tahap pelaksanaan konstruksi \\
\hline $\mathrm{X} 1.5$ & Perubahan spesifikasi \\
\hline $\mathrm{X} 1.6$ & Kesalahan dalam perencanaan konstruksi \\
\hline $\mathrm{X} 1.7$ & Penghentian pekerjaan sementara \\
\hline $\mathrm{X} 1.8$ & Jadwal yang terlalu padat \\
\hline $\mathrm{X} 1.9$ & Kondisi bawah tanah yang berbeda terhadap hasil penyelidikan \\
\hline $\mathrm{X} 1.10$ & Spesifikasi atau kriteria design engineering yang kurang lengkap \\
\hline $\mathrm{X} 1.11$ & Perubahan pekerjaan yang telah selesai \\
\hline $\mathrm{X} 1.12$ & Rembesan air tanah saat proses penggalian \\
\hline $\mathrm{X} 1.13$ & Perubahan kondisi lapangan proyek \\
\hline $\mathrm{X} 1.14$ & Percepatan jadwal \\
\hline $\mathrm{X} 1.15$ & Peningkatan penyelidikan kondisi tanah \\
\hline $\mathrm{X} 1.16$ & Perubahan metode kerja \\
\hline $\mathrm{X} 1.17$ & Pertimbangan keselamatan kerja \\
\hline $\mathrm{X} 2$ & Faktor administrasi \\
\hline $\mathrm{X} 2.1$ & Koordinasi yang terlambat disampaikan \\
\hline $\mathrm{X} 2.2$ & Perubahan berdasarkan perlindungan lingkungan \\
\hline $\mathrm{X} 2.3$ & Konflik kontrak dan perselisihan \\
\hline $\mathrm{X} 2.4$ & Perubahan kebijakan politik/ekonomi pemerintah \\
\hline $\mathrm{X} 2.5$ & Kontrak yang tidak lengkap \\
\hline $\mathrm{X} 2.6$ & Pasal-pasal kontrak yang kurang jelas \\
\hline $\mathrm{X} 2.7$ & Pengiriman material yang tidak sesuai spesifikasi \\
\hline X3 & Faktor pihak yang terlibat \\
\hline $\mathrm{X} 3.1$ & Percepatan pekerjaan atas perintah owner \\
\hline $\mathrm{X} 3.2$ & Kebijakan peraturan dari pihak owner \\
\hline $\mathrm{X} 3.3$ & Jadwal owner terlambat \\
\hline $\mathrm{X} 3.4$ & Penundaan pekerjaan karena permintaan owner \\
\hline $\mathrm{X} 3.5$ & Kegagalan owner menyediakan sites, alat atau material \\
\hline X3.6 & jadwal kontraktor terlambat \\
\hline $\mathrm{X} 3.7$ & Intervensi pihak ketiga \\
\hline $\mathrm{X} 3.8$ & Kinerja pihak ketiga yang kurang baik \\
\hline $\mathrm{X} 4$ & Faktor lain-lain \\
\hline $\mathrm{X} 4.1$ & Kejadian tak terduga seperti kebakaran atau kerusakan pada alat berat \\
\hline $\mathrm{X} 4.2$ & Cuaca buruk \\
\hline $\mathrm{X} 4.3$ & Penurunan tanah \\
\hline $\mathrm{X} 4.4$ & Bencana alam \\
\hline $\mathrm{X} 4.5$ & Konflik antar buruh \\
\hline Y1 & Indikator cco \\
\hline Y1.1 & Penambahan biaya proyek \\
\hline Y1.2 & Penundaan penyelesaian proyek \\
\hline Y1.3 & Pengerjaan ulang dan pembongkaran \\
\hline Y1.4 & Penurunan kualitas pekerjaan \\
\hline Y1.5 & Penurunan produktivitas \\
\hline
\end{tabular}




\section{Analisis data PLS-SEM}

Setelah penginputan data serta pembuatan konstruk pada program smartPLS, lalu dilakukan perhitungan data, maka didapat hasil yang dapat dilihat pada gambar 2.

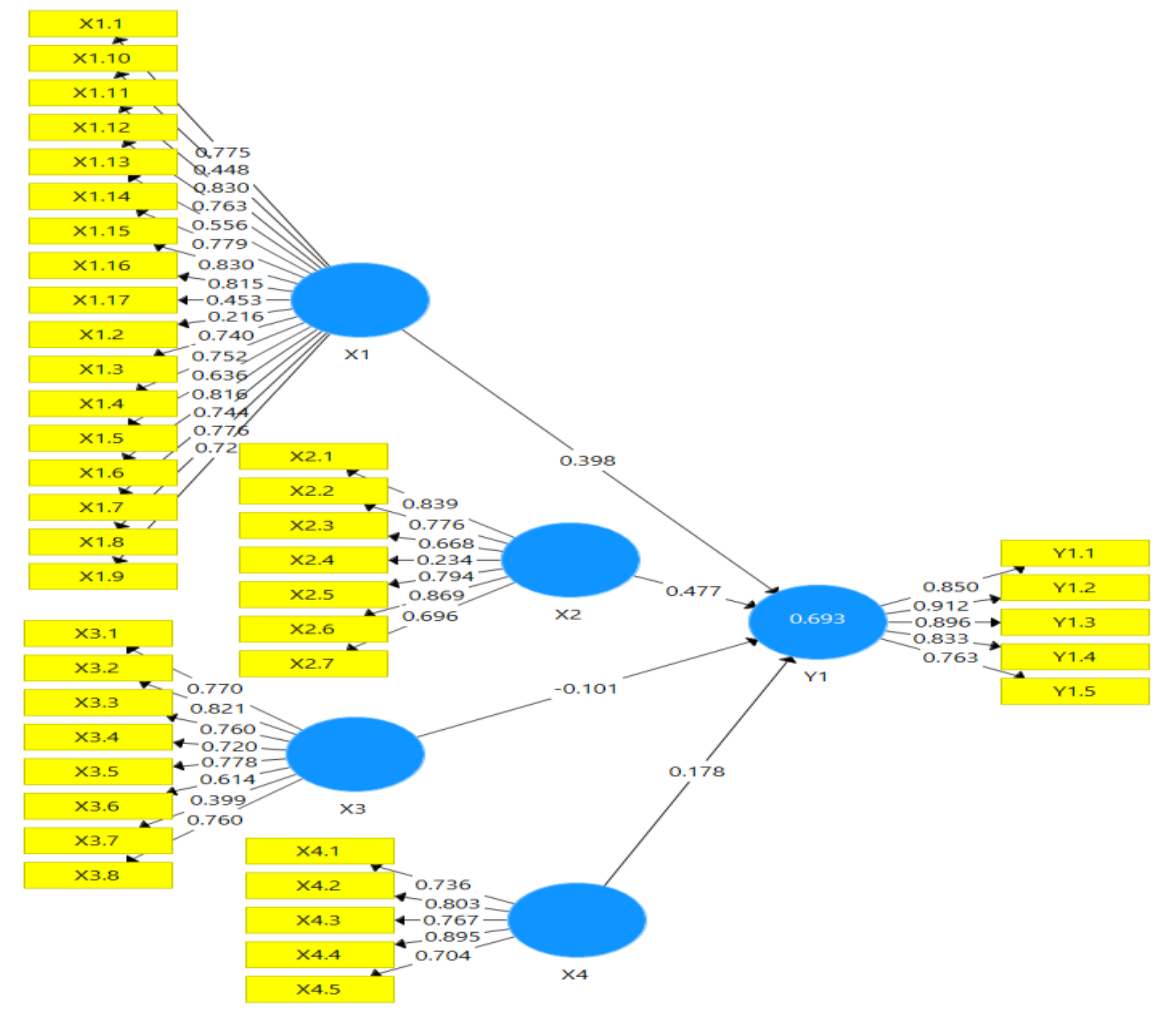

Gambar 2. Path modeling

\section{Outer model}

Penilaian bagian luar (outer model) terdiri dari beberapa bagian. Penilaian pertama dimulai dengan pengecekan nilai reliabilitas dan validitas konvergen guna mengetahui apakah indikator mendasari variabel laten tersebut. Kemudian dilanjutkan dengan pengecekan validitas diskriminan untuk menunjukan keterbedaan antara dua konsep yang berbeda secara konseptual. Namun untuk melihat apakah terdapat pereduksian data dilakukan pengecekan terhadap outer loading yang dapat dilihat pada tabel 2.

Tabel 2. Outer loadings

\begin{tabular}{|c|c|c|c|c|c|}
\hline & $\mathrm{X} 1$ & $\mathrm{X} 2$ & X3 & $\mathrm{X} 4$ & Y1 \\
\hline X1.1 & 0,775 & & & & \\
\hline $\mathrm{X} 1.10$ & 0,448 & & & & \\
\hline $\mathrm{X} 1.11$ & 0,830 & & & & \\
\hline $\mathrm{X} 1.12$ & 0,763 & & & & \\
\hline $\mathrm{X} 1.13$ & 0,556 & & & & \\
\hline $\mathrm{X} 1.14$ & 0,779 & & & & \\
\hline $\mathrm{X} 1.15$ & 0,830 & & & & \\
\hline $\mathrm{X} 1.16$ & 0,815 & & & & \\
\hline $\mathrm{X} 1.17$ & 0,453 & & & & \\
\hline $\mathrm{X} 1.2$ & 0,216 & & & & \\
\hline X1.3 & 0,740 & & & & \\
\hline X1.4 & 0,752 & & & & \\
\hline $\mathrm{X} 1.5$ & 0,636 & & & & \\
\hline X1.6 & 0,816 & & & & \\
\hline X1.7 & 0,744 & & & & \\
\hline
\end{tabular}


Tabel 2. Outer loadings (Lanjutan)

\begin{tabular}{|c|c|c|c|c|c|}
\hline & $\mathrm{X} 1$ & $\mathrm{X} 2$ & $\mathrm{X} 3$ & $\mathrm{X} 4$ & Y1 \\
\hline $\mathrm{X} 1.8$ & 0,776 & & & & \\
\hline X1.9 & 0,721 & & & & \\
\hline $\mathrm{X} 2.1$ & & 0,839 & & & \\
\hline $\mathrm{X} 2.2$ & & 0,776 & & & \\
\hline $\mathrm{X} 2.3$ & & 0,668 & & & \\
\hline $\mathrm{X} 2.4$ & & 0,234 & & & \\
\hline $\mathrm{X} 2.5$ & & 0,794 & & & \\
\hline $\mathrm{X} 2.6$ & & 0,869 & & & \\
\hline $\mathrm{X} 2.7$ & & 0,696 & & & \\
\hline X3.1 & & & 0,770 & & \\
\hline X3.2 & & & 0,821 & & \\
\hline X3.3 & & & 0,760 & & \\
\hline X3.4 & & & 0,720 & & \\
\hline X3.5 & & & 0,778 & & \\
\hline X3.6 & & & 0,614 & & \\
\hline X3.7 & & & 0,399 & & \\
\hline X3.8 & & & 0,760 & & \\
\hline $\mathrm{X} 4.1$ & & & & 0,736 & \\
\hline $\mathrm{X} 4.2$ & & & & 0,803 & \\
\hline $\mathrm{X} 4.3$ & & & & 0,767 & \\
\hline $\mathrm{X} 4.4$ & & & & 0,895 & \\
\hline $\mathrm{X} 4.5$ & & & & 0,704 & \\
\hline Y1.1 & & & & & 0,850 \\
\hline Y1.2 & & & & & 0,912 \\
\hline Y1.3 & & & & & 0,896 \\
\hline Y1.4 & & & & & 0,833 \\
\hline Y1.5 & & & & & 0,763 \\
\hline
\end{tabular}

Outer loadings (muatan luar) memiliki nilai minimal sebesar 0,5 , karena setiap variabel laten dapat menjelaskan varian indikatornya masing-masing setidak-tidaknya sebesar 50\% (Sarwono dan Narimawati, 2015). Apabila nilainya kurang dari 0,5, maka indikator tersebut dihapuskan karena dianggap tidak dapat menjelaskan variabel laten yang dimaksud. Berdasarkan hasil outer loadings diatas maka:

- Pada faktor konstruksi (X1), terdapat 3 indikator yang memiliki nilai loading factor dibawah 0,5, yaitu pekerjaan tambahan untuk pekerjaan dibawah tanah (X1.2), spesifikasi atau kriteria design engineering yang kurang lengkap (X1.10), dan pertimbangan keselamatan kerja (X1.17), sedangkan indikator lainnya memiliki nilai diatas 0,5 . Oleh karena itu ketiga indikator tersebut harus dihilangkan atau direduksi.

- Pada faktor administrasi (X2), terdapat 1 indikator yang memiliki nilai loading factor dibawah 0,5, yaitu perubahan kebijakan politik/ ekonomi pemerintah (X2.4), sedangkan indikator lainnya memiliki nilai di atas 0,5 .

- Pada faktor pihak yang terlibat (X3), terdapat 1 indikator yang memiliki nilai loading factor dibawah 0,5, yaitu intervensi pihak ketiga (X3.7), sedangkan indikator lainnya memiliki nilai di atas 0,5.

- Pada faktor lain-lain (X4) dan change order (Y1), seluruh indikator memiliki nilai loading factor di atas 0,5. Oleh karena itu tidak diperlukan pereduksian indikator.

Dikarenakan terdapat penghilangan beberapa indikator dari konstruk awal, maka diperlukan perhitungan ulang guna mengetahui nilai outer loadings yang didapat. Hasil perhitungan dapat dilihat pada gambar 3 . 


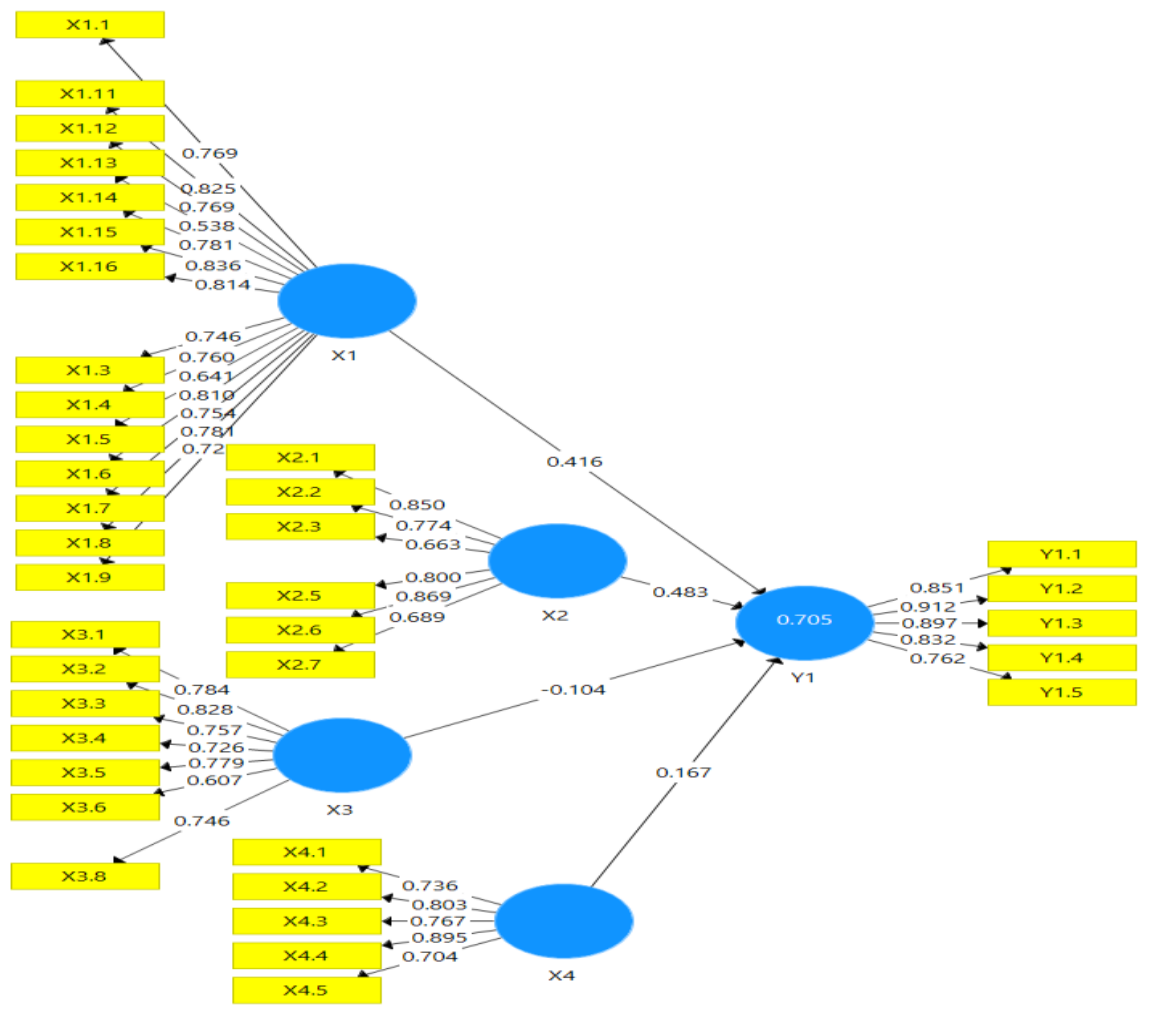

Gambar 3. Perhitungan lanjutan

Langkah selanjutnya adalah melakukan pengecekan reliabilitas, validitas konvergen dan validitas diskriminan, guna mengetahui apakah permodelan dapat dipakai atau tidak. Nilai reliabilitas dapat dilihat pada tabel 3.

Tabel 3. Construct reliability

\begin{tabular}{lcc}
\hline & Cronbach's alpha & Composite reliability \\
\hline $\mathrm{X} 1$ & 0,942 & 0,949 \\
$\mathrm{X} 2$ & 0,867 & 0,901 \\
$\mathrm{X} 3$ & 0,870 & 0,899 \\
$\mathrm{X} 4$ & 0,841 & 0,888 \\
\hline $\mathrm{Y} 1$ & 0,905 & 0,930 \\
\hline
\end{tabular}

Berdasarkan tabel diatas disimpulkan bahwa seluruh variabel laten bernilai sangat andal karena memiliki nilai cronbach's alpha berkisar antara 0,8 - 1,0 dan memiliki nilai pengaruh konsistensi internal masuk kriteria yaitu diatas 0,6 .

Selain pengecekan nilai reliabilitas, perlu juga diperiksa validitas. Pengecekan nilai validitas dapat dilihat pada nilai AVE (average variance extracted). Nilai AVE digunakan untuk pengecekan validitas konvergen yang menentukan apakah variabel laten mampu menjelaskan lebih setengah variabel indikatornya. Nilai AVE dapat dilihat pada tabel 4.

Tabel 4. Average variance extracted

\begin{tabular}{cccccc}
\hline & X1 & X2 & X3 & X4 & Y1 \\
\hline AVE & 0,573 & 0,605 & 0,562 & 0,614 & 0,727 \\
\hline
\end{tabular}

Berdasarkan tabel 4, nilai AVE semua variabel laten berada di atas 0,5. Hal ini menunjukan validitas konvergen yang memadai dan memiliki arti bahwa satu variabel laten mampu menjelaskan lebih dari setengah varian dari indikator-indikatornya dalam rata-rata.

Setelah pengecekan validitas konvergen dan reliabilitas selesai, selanjutnya dilakukan pengecekan validitas diskriminan. Cross loadings digunakan untuk mengecek validitas diskriminan yang apabila nilai indikator memiliki 
korelasi lebih tinggi dengan variabel laten lainnya daripada variabel latennya sendiri maka kecocokan model harus di pertimbangkan (Sarwono dan Narimawati, 2015). Nilai cross loadings dapat dilihat pada tabel 5.

Tabel 5. Cross loadings

\begin{tabular}{|c|c|c|c|c|c|}
\hline & $\mathrm{X} 1$ & $\mathrm{X} 2$ & $\mathrm{X} 3$ & $\mathrm{X} 4$ & Y1 \\
\hline X1.1 & $\mathbf{0 , 7 6 9}$ & 0,500 & 0,394 & 0,409 & 0,571 \\
\hline X1.11 & $\mathbf{0 , 8 2 5}$ & 0,529 & 0,532 & 0,577 & 0,698 \\
\hline $\mathrm{X} 1.12$ & 0,769 & 0,434 & 0,428 & 0,596 & 0,619 \\
\hline $\mathrm{X} 1.13$ & $\mathbf{0 , 5 3 8}$ & 0,317 & 0,381 & 0,418 & 0,312 \\
\hline $\mathrm{X} 1.14$ & $\mathbf{0 , 7 8 1}$ & 0,441 & 0,501 & 0,548 & 0,476 \\
\hline $\mathrm{X} 1.15$ & $\mathbf{0 , 8 3 6}$ & 0,301 & 0,387 & 0,437 & 0,526 \\
\hline $\mathrm{X} 1.16$ & $\mathbf{0 , 8 1 4}$ & 0,420 & 0,566 & 0,549 & 0,641 \\
\hline $\mathrm{X} 1.3$ & 0,746 & 0,393 & 0,393 & 0,465 & 0,511 \\
\hline X1.4 & 0,760 & 0,382 & 0,470 & 0,432 & 0,529 \\
\hline X1.5 & 0,641 & 0,334 & 0,306 & 0,295 & 0,372 \\
\hline X1.6 & $\mathbf{0 , 8 1 0}$ & 0,482 & 0,468 & 0,444 & 0,660 \\
\hline X1.7 & $\mathbf{0 , 7 5 4}$ & 0,460 & 0,356 & 0,622 & 0,563 \\
\hline $\mathrm{X} 1.8$ & $\mathbf{0 , 7 8 1}$ & 0,481 & 0,454 & 0,432 & 0,518 \\
\hline X1.9 & $\mathbf{0 , 7 2 3}$ & 0,448 & 0,473 & 0,610 & 0,622 \\
\hline $\mathrm{X} 2.1$ & 0,533 & $\mathbf{0 , 8 5 0}$ & 0,681 & 0,368 & 0,640 \\
\hline $\mathrm{X} 2.2$ & 0,456 & 0,774 & 0,581 & 0,320 & 0,662 \\
\hline $\mathrm{X} 2.3$ & 0,479 & 0,663 & 0,529 & 0,379 & 0,490 \\
\hline $\mathrm{X} 2.5$ & 0,346 & $0, \mathbf{8 0 0}$ & 0,603 & 0,374 & 0,545 \\
\hline $\mathrm{X} 2.6$ & 0,263 & $\mathbf{0 , 8 6 9}$ & 0,540 & 0,381 & 0,466 \\
\hline $\mathrm{X} 2.7$ & 0,514 & $\mathbf{0 , 6 8 9}$ & 0,377 & 0,562 & 0,528 \\
\hline X3.1 & 0,372 & 0,658 & $\mathbf{0 , 7 8 4}$ & 0,244 & 0,500 \\
\hline X3.2 & 0,366 & 0,575 & $\mathbf{0 , 8 2 8}$ & 0,378 & 0,455 \\
\hline X3.3 & 0,555 & 0,578 & $\mathbf{0 , 7 5 7}$ & 0,321 & 0,473 \\
\hline X3.4 & 0,245 & 0,411 & 0,726 & 0,282 & 0,310 \\
\hline X3.5 & 0,511 & 0,532 & 0,779 & 0,420 & 0,446 \\
\hline X3.6 & 0,446 & 0,431 & $\mathbf{0 , 6 0 7}$ & 0,201 & 0,210 \\
\hline X3.8 & 0,541 & 0,523 & $\mathbf{0 , 7 4 6}$ & 0,612 & 0,447 \\
\hline $\mathrm{X} 4.1$ & 0,544 & 0,467 & 0,257 & $\mathbf{0 , 7 3 6}$ & 0,515 \\
\hline $\mathrm{X} 4.2$ & 0,711 & 0,417 & 0,391 & $\mathbf{0 , 8 0 3}$ & 0,516 \\
\hline $\mathrm{X} 4.3$ & 0,488 & 0,441 & 0,547 & $\mathbf{0 , 7 6 7}$ & 0,472 \\
\hline $\mathrm{X} 4.4$ & 0,524 & 0,410 & 0,411 & $\mathbf{0 , 8 9 5}$ & 0,541 \\
\hline $\mathrm{X} 4.5$ & 0,243 & 0,228 & 0,270 & $\mathbf{0 , 7 0 4}$ & 0,424 \\
\hline Y1.1 & 0,561 & 0,553 & 0,438 & 0,410 & 0,851 \\
\hline $\mathrm{Y} 1.2$ & 0,620 & 0,585 & 0,436 & 0,496 & $\mathbf{0 , 9 1 2}$ \\
\hline Y1.3 & 0,677 & 0,738 & 0,685 & 0,500 & 0,897 \\
\hline Y1.4 & 0,593 & 0,667 & 0,521 & 0,687 & 0,832 \\
\hline Y1.5 & 0,674 & 0,530 & 0,297 & 0,578 & $\mathbf{0 , 7 6 2}$ \\
\hline
\end{tabular}

Dari tabel tersebut dapat disimpulkan bahwa nilai indikator memiliki korelasi lebih tinggi dengan variabel latennya sendiri daripada variabel laten lainnya, sehingga konstruk dari pemodelan PLS-SEM ini dapat digunakan.

Metode lain untuk menilai discriminant validity adalah membandingkan nilai square root of average variance extracted (AVE) setiap konstruk dengan korelasi antara konstruk dengan konstruk lainnya dalam model (Ghozali, 2014). Jika nilai akar kuadrat AVE setiap konstruk lebih besar daripada nilai korelasi antar konstruk dengan konstruk lainnya dalam model, maka dikatakan memiliki nilai discriminant validity yang baik. Hasil perhitungan dapat dilihat pada tabel 6. 
Tabel 6. Fornell-larcker criterion

\begin{tabular}{cccccc}
\hline & X1 & X2 & X3 & X4 & Y1 \\
\hline X1 & $\mathbf{0 , 7 5 7}$ & & & & \\
X2 & 0,565 & $\mathbf{0 , 7 7 8}$ & & & \\
X3 & 0,581 & 0,719 & $\mathbf{0 , 7 4 9}$ & & \\
X4 & 0,652 & 0,507 & 0,480 & $\mathbf{0 , 7 8 4}$ & \\
\hline Y1 & 0,737 & 0,727 & 0,565 & 0,633 & $\mathbf{0 , 8 5 3}$ \\
\hline
\end{tabular}

Dari tabel tersebut dapat disimpulkan bahwa nilai indikator memiliki korelasi lebih tinggi dengan variabel latennya sendiri daripada variabel laten lainnya, sehingga discriminant validity terpenuhi.

\section{Inner model}

Langkah selanjutnya dilakukan uji multikolinearitas dengan melihat nilai collinearity statistics (VIF). Pengujian terjadi atau tidaknya multikolinieritas antar variabel menggunakan nilai VIF. Jika nilai VIF > 10 terjadi kolinieritas antar variabel laten. Nilai inner VIF values dapat dilihat pada tabel 7.

Tabel 7. Inner VIF values

\begin{tabular}{|c|c|c|c|c|c|}
\hline & X1 & $\mathrm{X} 2$ & X3 & $\mathrm{X} 4$ & Y1 \\
\hline X1 & & & & & 2,125 \\
\hline $\mathrm{X} 2$ & & & & & 2,275 \\
\hline X3 & & & & & 2,286 \\
\hline $\mathrm{X} 4$ & & & & & 1,834 \\
\hline $\mathrm{Y} 1$ & & & & & \\
\hline
\end{tabular}

Berdasarkan tabel 7, tidak ada variabel laten yang memiliki nilai VIF diatas 10, sehingga dapat disimpulkan bahwa data terbebas dari multikolinearitas.

Selanjutnya dilakukan pengecekan dan pengukuran model struktural. Model struktural (inner model) merupakan model yang menggambarkan hubungan antar variabel laten yang dievaluasi menggunakan koefisien jalur, R-square, dan F-square. Dimana nilai-nilai tersebut dapat dilihat pada tabel 8, tabel 9, dan tabel 10.

Tabel 8. Path coefficients

\begin{tabular}{cccccc}
\hline & $\mathrm{X} 1$ & $\mathrm{X} 2$ & $\mathrm{X} 3$ & $\mathrm{X} 4$ & $\mathrm{Y} 1$ \\
\hline $\mathrm{X} 1$ & & & & & 0,416 \\
$\mathrm{X} 2$ & & & & & 0,483 \\
$\mathrm{X} 3$ & & & & & $-0,104$ \\
$\mathrm{X} 4$ & & & & & 0,167 \\
\hline $\mathrm{Y} 1$ & & & & \\
\hline
\end{tabular}

Dari nilai path coefficients diatas didapat inner model sebagai berikut :

$\mathrm{Y} 1=0,416 \mathrm{X} 1+0,483 \mathrm{X} 2-0,104 \mathrm{X} 3+0,167 \mathrm{X} 4+\delta$

Tabel 9. R-square

\begin{tabular}{cc}
\hline & R-Square \\
\hline Y1 & 0,705 \\
\hline
\end{tabular}

Nilai $R^{2}$ untuk change order (Y1) 0,705, dimana angka tersebut menjelaskan bahwa variabilitas variabel endogen yang dapat dijelaskan oleh variabilitas variabel eksogen sebesar 70,5\%. Nilai $R^{2}$ sebesar $>0,7$ dikategorikan sebagai kuat.

Setelah memeriksa $R^{2}$, dilakukan pemeriksaan terkait pengaruh variabel endogen terhadap variabel eksogen yang dapat diketahui berdasarkan nilai effect size $F^{2}$. 
Tabel 10. F-square

\begin{tabular}{cccccc}
\hline & $\mathrm{X} 1$ & $\mathrm{X} 2$ & $\mathrm{X} 3$ & $\mathrm{X} 4$ & $\mathrm{Y} 1$ \\
\hline $\mathrm{X} 1$ & & & & & 0,276 \\
$\mathrm{X} 2$ & & & & & 0,347 \\
$\mathrm{X} 3$ & & & & & 0,016 \\
$\mathrm{X} 4$ & & & & & 0,052 \\
\hline $\mathrm{Y} 1$ & & & & & \\
\hline
\end{tabular}

Berdasarkan tabel diatas diperoleh kesimpulan sebagai berikut:

- Variabel laten X1 memiliki pengaruh kuat sebagai variabel prediktor (variabel laten eksogenous) pada tataran struktural.

- Variabel laten X2 memiliki pengaruh kuat sebagai variabel prediktor (variabel laten eksogenous) pada tataran struktural.

- Variabel laten X3 memiliki pengaruh lemah sebagai variabel prediktor (variabel laten eksogenous) pada tataran struktural.

- Variabel laten X4 memiliki pengaruh cukup sebagai variabel prediktor (variabel laten eksogenous) pada tataran struktural.

Selanjutnya dilakukan uji $\mathrm{T}$ untuk mengentahui hubungan pengaruh antar variabel laten menggunakan program hitung bootstraping SmartPLS 3.0. Agar nilai T stabil diharuskan subsamples lebih besar dari 500, sehingga dilakukan bootstraping dengan jumlah subsamples sebesar 1500 untuk menjamin kestabilan nilai T. Hasil perhitungan bootstraping dapat dilihat pada tabel 11.

Tabel 11. Hasil bootstraping

\begin{tabular}{|c|c|c|c|c|c|}
\hline & $\begin{array}{l}\text { Original Sample } \\
(\mathrm{O})\end{array}$ & $\begin{array}{l}\text { Sample Mean } \\
(\mathrm{M})\end{array}$ & $\begin{array}{c}\text { Standard Deviation } \\
\text { (STDEV) }\end{array}$ & $\begin{array}{c}\text { T Statistics } \\
(\mid \mathrm{O} / \text { STDEV } \mid)\end{array}$ & $\begin{array}{c}\mathrm{P} \\
\text { Values }\end{array}$ \\
\hline $\begin{array}{c}\mathrm{X} 1 \text {-> } \\
\mathrm{Y} 1\end{array}$ & 0,416 & 0,386 & 0,144 & 2,881 & 0,004 \\
\hline $\begin{array}{c}\mathrm{X} 2 \text {-> } \\
\mathrm{Y} 1\end{array}$ & 0,483 & 0,453 & 0,174 & 2,773 & 0,006 \\
\hline $\begin{array}{c}\mathrm{X} 3 \text {-> } \\
\mathrm{Y} 1\end{array}$ & $-0,104$ & $-0,058$ & 0,148 & 0,708 & 0,479 \\
\hline $\begin{array}{c}\mathrm{X} 4 \text {-> } \\
\mathrm{Y} 1\end{array}$ & 0,167 & 0,197 & 0,135 & 1,236 & 0,216 \\
\hline
\end{tabular}

Berdasarkan tabel 11, diperoleh hubungan faktor konstruksi (X1) terhadap change order (Y1) signifikan karena memiliki $\mathrm{P}$ value $<0,05$, hubungan faktor administrasi (X2) dengan change order $(\mathrm{Y} 1)$ signifikan karena memiliki $\mathrm{P}$ value $<0,05$. Sedangkan hubungan faktor pihak yang terlibat (X3) dan faktor lain-lain (X4) terhadap change order (Y1) tidak signifikan karena memiliki P values $>0,05$

\section{KESIMPULAN DAN SARAN}

\section{Kesimpulan}

Berdasarkan analisis data dan hasil pengolahan yang dilakukan dengan bantuan program SmartPLS 3.0, dihasilkan beberapa kesimpulan yang sesuai dengan tujuan penelitian, yaitu:

- Terdapat 2 faktor yang berpengaruh signifikan terhadap change order yaitu faktor konstruksi dan faktor administrasi. Sedangkan faktor pihak yang terlibat dan faktor lain-lain tidak berpengaruh signifikan terhadap change order.

- Faktor eksternal yang paling berpengaruh terhadap change order adalah:

- Faktor konstruksi:

- Peningkatan penyelidikan kondisi tanah

- Perubahan pekerjaan yang telah selesai

- Perubahan metode kerja

- Faktor administrasi:

- Pasal-pasal kontrak yang kurang jelas 
- Koordinasi yang terlambat disampaikan

- Kontrak yang tidak lengkap

\section{Saran}

Berdasarkan penelitian yang telah dilakukan, terdapat beberapa saran sebagai berikut:

- Berdasarkan analisis yang dilakukan diketahui bahwa faktor konstruksi dan faktor administrasi merupakan faktor-faktor yang memiliki pengaruh signifikan terhadap change order. Untuk itu kepada pihak-pihak yang terlibat dalam suatu proyek konstruksi gedung bertingkat kedepannya diperlukan antisipasi lebih terhadap kedua faktor tersebut agar dapat meminimalisir kemungkinan terjadinya change order.

- Untuk penelitian selanjutnya, diharapkan memperbanyak jumlah sampel agar model yang dihasilkan dapat lebih merepresentasikan keadaan yang sebenarnya dan dapat lebih akurat sesuai dengan keadaan yang terjadi dalam dunia konstruksi. Serta menambahkan kembali variabel indikator melalui proses studi literatur, dengan harapan mampu memberikan pengetahuan mengenai faktor yang mempengaruhi change order dengan lebih akurat dan handal.

\section{DAFTAR PUSTAKA}

Alnuaimi, Ali S., et al. "Causes, Effects, Benefits, and Remedies of Change Orders on Public Construction Projects in Oman." Journal of Construction Engineering and Management, volume 136(5) (2010): 615-622.

Barrie, Donald S. dan Boyd C. Paulson. Professional Construction Management : Including CM, Design-Construct, and General Contracting; THIRD EDITION. Singapore: McGraw-Hill, 1992.

Ghozali, Imam. Structural Equation Modeling metode alternatif dengan PARTIAL LEAST SQUARES (PLS), Edisi 4. Semarang: Universitas Diponegoro Semarang, 2014.

Hanna, Awad S., et al. "Impact of Change Order on Labor Efficiency for Mechanical Construction." Journal of Construction Engineering and Management, 125 (1992): 176-184.

Hansen, Seng. Manajemen Kontrak Konstruksi; Cetakan Ketiga Edisi Revisi. Jakarta: PT Gramedia Pustaka Utama, 2017.

Hsieh, Ting-ya, Shih-tong Lu dan Chao-hui Wu. "Statistical Analysis of Causes for Change Orders in Metropolitan Public Works.” International Journal of Project Management, volume 22 (2004): 679-686.

Sapulette, W. "Analisa Penyebab dan Pengaruh Change Order pada Proyek Infrastruktur dan Bangunan Gedung di Ambon.” Jurnal TEKNOLOGI, Volume 6 Nomor 2 (2009): 627 - 633.

Sarwono dan Narimawati. Membuat Skripsi, Tesis dan Disertasi dengan Partial Least Square SEM (PLS-SEM). Yogyakarta: Penerbit Andi, 2015.

Sulistio, H dan Waty. "Analysis and Evaluation Change Order in Flexible Pavement (Case Study: Road Projects in East Kalimantan).” MEDIA KOMUNIKASI TEKNIK SIPIL, vol. 16, no. 1 (2008): 31-47.

Sulistio, H dan Wibowo. "Pengaruh Model Change Order pada Kehilangan Produktivitas dan Performa Proyek Konstruksi Jalan dari Perspektif System Teori.” MEDIA KOMUNIKASI TEKNIK SIPIL, vol. 17, no. 3 (2009): 285-293. 